\title{
A Integração e o Desenvolvimento da Região Sul e o Ministério do Interior
}

\author{
JOSÉ COSTA CAVALCANTI
}

Ministro do Interior

A palavra integração não é nova na linguagem governamental brasileira. Seu sentido, porém, aprofundou-se e ampliou-se na semântica da política de desenvolvimento do atual Govêrno.

Integração hoje significa comunhão de todos os brasileiros, exprime solidariedade no crescimento, quer econômico, quer social, tanto em referência aos bens materiais e ocupação do território, quanto aos valôres culturais, abrangendo, por assim dizer, o corpo e a alma da Nação.

Sob êste enfoque, ela oferece uma visão panorâmica dos problemas nacionais em proporções exatas, de forma a medirse $\circ$ grau de relevância de cada um no quadro global, evitando-se ênfases apriorísticas e omissões prejudiciais em que a parte é destacada do todo. De outro ângulo, permite aproximaCõos e destaques setoriais necessários ao perfeito conhecimento da matéria em exame, de modo a dissipar imagens duvidosas, em que o todo absorve ou obscurece aspectos de importância fundamental.

Com base nessas premissas, o Govêrno da União levantou os grandes problemas nacionais e estabeleceu uma escala de prioridades para saná-los a curto e médio prazos. Do acurado estudo que procedeu, resultou a Política de Integração Nacional, formalizada em dois Programas: de Integração Nacional e de Integração Social, que expressam o esfôrço de integração em diferentes dimensões.

Impôs-se o III Govêrno da Revolução a grande tarefa de minimizar os desniveis que se observam no País, e que são 
fruto em parte do incorreto aproveitamento dos recursos naturais e de distorções econômicas acumuladas em muitas décadas. Esta realidade conduziu-nos a duas frentes de atuação: a da melhoria da distribuição de renda, para assegurar a autenticidade e a viabilidade econômico-política do processo de expansão, e a da luta pela eliminação do subdesenvolvimento, visando à elevação das condições de vida do homem brasileiro.

Nessa mesma linha de intenções, originaram-se os estudos e a formulação dos programas tendentes à racional utilização dos nossos recursos naturais, à implantação de uma política de desenvolvimento urbano, ao fortalecimento da emprêsa, à segurança financeira do empregado, ao atendimento das necessidades básicas do indivíduo - alimentação, saúde, educação e habitação - tudo de acôrdo com a doutrina maior, ou seja, dentro das coordenadas de Integração para Desenvolver.

Exatamente para corrigir os desniveis existentes entre 0 Brasil Setentrional e o Brasil Meridional, a programação do Govêrno contempla mais de perto, em sua primeira fase, a situação do Nordeste e da Amazônia, propondo-se a engajar o primeiro de forma efetiva ao processo de desenvolvimento que está transformando o País numa potência auto-suficiente e com vistas a uma ocupação e integração racionais da segunda.

A construção das rodovias Transamazônica e Cuiabá-Santarém, associada aos planos de colonização de extensas faixas marginais e de irrigação dos vales úmidos do Nordeste, representam os projetos prioritários do Programa de Integração Nacional, hoje em plena e vitoriosa realização.

Quanto ao Programa de Integração Social - instrumento hábil para que se implante, no Brasil, uma sociedade econômicamente aberta - visa assegurar a participação dos trabalhadores do setor privado no produto nacional, sob a forma de um fundo especial que, ademais, servirá de estímulo à formação do patrimônio familiar dos trabalhadores, favorecerá a melhoria das relações entre capital e trabalho, contribuindo ainda para o fortalecimento da emprêsa privada, inclusive pela aplicação do fundo em financiamentos de capital de giro.

Ambos os Programas são hoje esplêndidas realidades, de caráter político, social e econômico, em decorrência das quais - Brasil procura tomar posse efetiva do seu imenso território e os trabalhadores nacionais passam a partilhar, em proporções mais justas, dos bens gerados pelo seu labor. 


\section{INTEGRAÇÃO E DESENVOLVIMENTO REGIONAL}

Embora relativamente próspera, com renda equivalente a $18 \%$ do montante nacional numa área inferior a $7 \%$ do território brasileiro, a macrorregião compreendida pelos Estados do Paraná, Santa Catarina e Rio Grande do Sul não poderia ser deixada ao sabor de sua marcha espontânea, em têrmos de região. Tivesse o Govêrno Federal decidido não intervir no seu progresso de crescimento, êste possivelmente prosseguiria, mas a um maior custo. Pagaríamos o preço da lentidão, do desacêrto de medidas isoladas, de gastos paralelos, da não melhor aplicação de recursos e, sobretudo, de desencontradas políticas de desenvolvimento.

Êste o sentido essencial e o objetivo precípuo que presidiu à criação, em 1967, da Superintendência do Desenvolvimento da Região Sul - SUDESUL - em forma de autarquia vinculada ao Ministério do Interior, com a atribuição específica de planejar e coordenar o desenvolvimento regional, promovendo e acelerando a ascensão econômica e o bem-estar social das populações do extremo Sul.

Em menos de cinco anos de atividades, a SUDESUL mostra sua presença em muitos dos setores produtivos da sociedade sulina. Utilizando uma metodologia específica, em que a técnica de planejamento se alia à tática de ação.

A SUDESUL sabe que não basta planejar o desenvolvimento para que êste se faça; é indispensável que os planos sejam postos em execução.

Temos, na nossa história, um episódio muito expressivo a ilustrar esta verdade. Ocorreu no século XVIII, nos tempos do Brasil colonial, quando teve lugar o que se poderá considerar talvez como o primeiro planejamento governamental para 0 desenvolvimento desta região.

Referimo-nos à planificação do povoamento do litoral sulbrasileiro por vultoso contingente originário do arquipélago dos Açôres, levada a efeito pelo Conselho Ultramarino de Portugal.

Quem compulsa a copiosa documentação reunida sôbre a matéria surpreende-se com as sutilezas do plano, a preocupação do pormenor significativo, o conhecimento, notável para a época, de peculiaridades inerentes à técnica de planejamento a longo prazo. 
Tudo isto causa admiração e merece louvor. Contudo, já assim não foi quanto à segunda parte da operação, ou seja, a executiva, sèriamente prejudicada por uma série de erros.

O planejamento foi sem dúvida bom, até mesmo excelente face às limitações da época, porém sofreu sensíveis falhas em sua implantação, preponderantemente devidas ao despreparo dos homens aos quais se cometeu a tarefa de torná-lo efetivo.

Essa página histórica é portadora de uma lição aos técnicos da atualidade. Adverte-nos de que, por mais e melhor que se planeje, pouco ou nada valerá o nosso esfôrço criativo se não soubermos concretizar o idealismo e só projetar o que fôr realizável.

Seguindo diretrizes em que a tônica de ação está na exeqüibilidade dos planos, a SUDESUL vem cumprindo seu programa de trabalho, entrosada com os demais órgãos públicos e instituições particulares, numa progressão de atividade resultante, em boa parte, do revigoramento que lhe proporciona o apoio cada vez maior do Banco Regional de Desenvolvimento do Extremo Sul.

\section{PLANO DE DESENVOLVIMENTO DO SUL}

Em breve e pela primeira vez o Sul do País terá um plano de desenvolvimento regional, envolvendo a ação do Govêrno nas esferas federal e estadual, além da iniciativa privada, para o período de 1972 a 1974. Elaborado pela SUDESUL, segundo orientação emanada dos Ministérios do Interior e do Planejamento e Coordenação Geral, o Plano de Desenvolvimento do Sul representa uma radiografia dos problemas sócio-econômicos da área regional, em circunstanciada análise que conduziu à fixação de uma doutrina de trabalho e permitiu eleger os projetos prioritários que irão expressá-la.

Trata-se de estudo procedido com a preocupação de objetividade e rigor técnico, o que lhe confere características de instrumento hábil e ao mesmo tempo flexível e idôneo para 0 planejamento integrado da macrorregião.

O plano preconiza a intensificação do conhecimento dos recursos produtivos, o estimulo à modernização e ao incremento do setor primário, a ampliação e o aperfeiçoamento dos serviços de infra-estrutura econômica e social. Aconselha também a adoção de uma política diretora do crescimento dos centros urbanos - problema que, dia a dia, assume proporções mais inquietantes na Região e no País - mediante a promoção de 
pesquisas aptas a facultar o encontro de soluções social e econômicamente corretas.

No setor agropecuário, o PDS recomenda a mudança da estrutura existente, com o estabelecimento de emprêsas rurais e outros tipos de exploração que favoreçam o uso de tecnologia mais avançada. De outra parte, prevê as possibilidades de criação de distritos industriais vinculados a complexos de indústrias integradas, preferencialmente voltadas para os setores da química, da mecânica e da metalurgia. Salienta, outrossim, a necessidade de instituir-se, em coordenação com o Ministério da Agricultura, centros estaduais de planejamento agrícola junto às Secretarias de Agricultura do Paraná, de Santa Catarina e do Rio Grande do Sul. Por outro lado, através de um programa de reestruturação econômica, na área dos minifúndios, o PDS busca viabilizar formas e mecanismos tendentes a atingir escalas adequadas de operação, abrangendo zonas específicas dos três Estados sulinos.

Ainda no âmbito agropecuário, o documento ressalta a preservação e o emprêgo racional dos recursos naturais, indicando, em relação ao Estado do Paraná, a conveniência de estudos integrados a fim de conciliar-se as atividades agrícolas - pecuárias do noroeste daquele Estado à vocação natural dos solos, objetivando maior produtividade e eliminação de processos predatórios no aproveitamento dos recursos naturais.

feistema de transportes e os meios apropriados a apergaçó-lo, em diferentes prazos, constituem matéria de investigação e equacionamento pelo PDS, bem como todos os aspectos significativos da sócio-economia regional, destacando-se planejamento local integrado, desenvolvimento de comunidade e recursos humanos.

PROJETO SUDOESTE I

ta-se, Dentre os planos de implantação pela SUDESUL, salienmia gaú sua importância para o impulsionamento da econoCêrca deúcha, o Projeto Sudoeste I, que abrange uma área de Estado. 72 mil km² e atinge 19 municipios do sudoeste dêste

A região escolhida é sujeita a sêcas e enchentes periódicas que afetam profundamente sua economia, e que se baseia nas atividades do setor primário.

fundapós a fase preliminar, que consistiu em estudos aprode pedologia, geologia, hidrologia, climatologia e 
sócio-economia rural, foi elaborado o Plano Diretor e programados dois projetos-pilôto e um projeto de desenvolvimento pròpriamente dito.

Estudos complementares indicaram os locais adequados à implantação dos projetos-pilôto, a saber: São Pedro do Sul, para atividades agrícolas, e Santana do Livramento, para atividades pecuárias. Os resultados positivos de ambos os projetos estão servindo para incrementar a produtividade na própria área experimental e representando informações básicas para a extensão do planejamento a outros pontos.

O projeto de desenvolvimento, previsto como terceira etapa pelo Plano Diretor, foi implantado no Município de Alegrete, considerado o mais representantivo de tôda a região do Projeto Geral. Mais que um simples projeto de desenvolvimento, reputamos o que a SUDESUL está realizando em Alegrete, por seu ineditismo quanto à técnica de planejamento e pelos efeitos que já se fazem sentir, um trabalho vigoroso, que poderá ser estendido a outras áreas do País.

A implantação do projeto inclui o entrosamento gradativo do setor agropecuário no processo de ascensão econômica, através de sistemática orientação aos fazendeiros selecionados pelo programa, além de procedimentos outros com vistas ao congraçamento das lideranças locais no sentido de criar um espírito de integração comunitária capaz de aglutinar vontades e polarizar interêsses em tôrno do empreendimento.

Resultados animadores estão sendo obtidos em Alegrete, tais como os conseguidos com os poços-teste, que proporcionaram o conhecimento da existência de mais de 20 bilhões de metros cúbicos de água subterrânea, a uma profundidade de até 160 metros. Observou-se, também, que a recarga anual dos lençóis subterrâneos é da ordem de 2 e meio bilhões de metros cúbicos de água, a permitir a implantação de até 3 mil poços, com vazão média de 100 mil litros por hora. A reserva aqüífera assegurará suprimento durante as mais longas sêcas, ou seja, até um máximo de 8 anos de completa estiagem.

Iniciou agora a SUDESUL o estágio de transferência de "know-how" e metodologia utilizados no projeto, para as instituições que deverão encarregar-se, paulatinamente, da continuldade executiva das operações.

A experiência adquirida está a indicar que a base para a ação executiva deve recair nas entidades oficiais e particulares de efetiva atuação na área, tais como Ministério da Agricultura, Secretaria de Agricultura, ASCAR, Universidades, Pre- 
feituras, associações e sindicatos rurais, estabelecimentos de crédito, cooperativas e outros órgãos responsáveis pelo desenvolvimento da região em que incide o Projeto.

Evidencia-se fundamental a participação de tôdas as mencionadas instituições na etapa de implantação dêsse Projeto Integrado, cujo êxito final indubitàvelmente dependerá da proporção de esforços conjugados que se obtiver.

A SUDESUL, doravante, competirá a tarefa de coordenar tais esforços, numa ação compatibilizadora característica de suas atribuições de órgão-meio, propiciador de condições técnicas para a aceleração do crescimento regional.

Apelamos a tôdas as entidades citadas a se associarem decididamente aos trabalhos do Projeto Sudoeste I, pois estamos convencidos de que sòmente com o seu indispensável concurso alcançará o sucesso desejado, exercendo ainda função irradiante no desenvolvimento de tão extensa área.

TURISMO

A 15 de agôsto de 1969, a SUDESUL firmou convênio com a EMBRATUR, chamando a si a responsabilidade da elaboração do Plano Regional de Turismo, a integrar-se no Plano Nacional.

Dentro de uma sistemática inovadora em sua concepção operacional, os estudos foram contratados com emprêsa espanhola de reconhecida experiência no setor. A singularidade maior do sistema adotado, porém, estêve na criação de um Grupo Consultivo, do qual participaram todos os organismos públicos e particulares diretamente interessados no assunto.

áreas esquematização dos trabalhos contemplou três grandes petiu a estudo, a identificar fases sucessivas. A primeira comque a parte referente a Informações, Análises e Problemática, oferta turísticas. Á segunda correspondeu a programação ou planejamento geral, que definiu as medidas de ação, as linhas Q diretrizes da política a ser seguida. Reservou-se à terceira etapa a realização de estudos sôbre projetos concretos, derivados dos parâmetros e objetivos indicados na fase de plane-
jamento.

A partir dos estudos procedidos, que envolveram aspectos globais, não só a nível regional, como também abrangendo pesquisas realizadas "in loco", junto aos principais centros emissores da demanda, foi possível apreciar-se o comportamento provável do fenômeno. 
A demanda total da Região Sul, na temporada 1970/71, alcançou mais de 500.000 turistas, dos quais cêrca de 100.000 procedentes do exterior e 400.000 nacionais, compreendendo tanto o fluxo intra-regional como o extra-regional. A extrapolação do crescimento da demanda ocorrido nos últimos anos $e$ as iniciativas preconizadas no sentido da dinamização do setor, permitem a previsão das seguintes taxas de incremento anual cumulativo: turismo intra-regional - $10 \%$ : turismo extra-regional $-15 \%$ : turismo exterior $-19 \%$.

As necessidades da oferta turística, em função dos objetivos, para o período cobtrto pelo Plano (1972/1975), traduzemse, em têrmos econômicos, num investimento global que atinge a cifra de 748 milhões de cruzeiros, compreendendo inversões em hotelaria, indústria complementar, infra-estrutura e promoção turística.

As inversões em hotéis montarão, aproximadamente, a 540 milhões de cruzeiros, $25 \%$ dos quais deverão provir de créditos do setor público (EMBRATUR, BRDE, incentivos fiscais e verbas orçamentárias consignadas pelos Estados) e $75 \%$ do setor privado.

Aspecto a ser salientado, por sua relevância, diz respeito à comparação entre as inversões do setor público e sua recuperação aos cofres públicos através do sistema tributário. Na temporada de 1971, o dispêndio foi da ordem de 390 milhões de cruzeiros, dos quais $60 \%$ sob a rubrica de "gastos hoteleiros" e $40 \%$ referentes a "gastos não hoteleiros". Tomando-se como parâmetros os gastos médios diários e o número de dias de permanência do turista na Região, e projetando os dados para o triênio, chegaremos a um ingresso total, no triênio, de 974 milhões de cruzeiros, aproximadamente.

Aceitando-se um efeito multiplicador de indice igual a 2 , concluiremos que a renda a ser produzida na Região, em decorrência da indústria do turismo, chegará a totalizar cêrca de 2 bilhões de cruzeiros, dos quais, através do sistema tributário, reverterão aos cofres públicos $25 \%$, ou sejam, 500 milhões de cruzeiros, em números redondos.

Finalmente, aludiremos ao importante aspecto do "emprêgo gerado na indústria turística", a fim de possibilitar uma idéia das repercussões sociais do Plano, não apenas no que se refere ao volume de novos empregos suscitados, mas igualmente no sentido da elevação dos niveis de vida.

Em função dos dados conhecidos e- da projeção para 0 futuro sob a forma de objetivos a colimar, a estimativa mínima 
de ocupação de mão-de-obra é de cêrca de 25 mil, sendo 6.250 empregos diretos e 18.750 indiretos, criados a partir da implantação do Plano.

Os números falam com eloqüência, mais que quaisquer palavras, dos promissores horizontes que a indústria turística descortina para a economia regional, mas não basta esta constatação nem será suficiente o fato de dispormos de um Plano bem elaborado. É imprescindivel que o esfôrço conjunto do poder público e da emprêsa privada dêem condições de realidade à visão prospectiva dos técnicos.

\section{DESENVOLVIMENTO MICRORREGIONAL}

Extremamente difícil ou mesmo impraticável seria para a SUDESUL estabelecer contacto direto com todos os 717 municípios que compõem a Região. Além disso, tal relacionamento resultaria inoperante, em grande parte, devido à carência de capacidade administrativa de elevado número dêles. Pode-se dizer, até, que a estrutura da maioria dos municípios é incipiente $\mathrm{e}$ desprovida de adequados padrões funcionais.

Todavia, são municípios, e suas sedes, se bem não sejam núcleos urbanos ponderáveis, têm legalmente "status" de cidade, com autonomia e atribuições definidas pela Constituição e pelas leis.

A realidade conduziu a SUDESUL a adotar como instrumento de ação, junto aos municípios, o agrupamento dêstes em associações, voltadas para os comuns interêsses e levando em conta as microrregiões homogêneas existentes.

Em decorrência do trabalho indutor da SUDESUL, que elabora projeto de estatuto e presta tôda a assistência necessária à organização e funcionamento das associações de municípios, intenso vem sendo o movimento de criação dessas entidades na área regional, hoje quase completamente por elas coberta Q que vêm se revelando de satisfatória eficiência na promoção do desenvolvimento local, na solução dos problemas comunitários e na implantação de programas instituídos pelo Ministério do Interior e pela SUDESUL.

Dentre êstes, figura o Programa de Ação Concentrada, Vuja finalidade específica é promover, por etapas, o desenvolvimento local integrado de comunidades urbanas, concentrando recursos em municípios considerados prioritários.

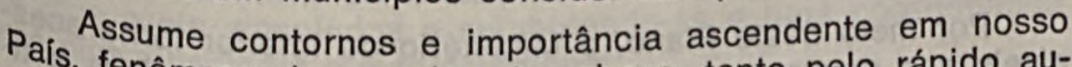
ais, fenômeno do crescimento urbano, tanto pelo rápido au- 
mento populacional, quanto pela concentração de atividades econômicas nas cidades, mas acima de tudo face à limitação imposta pela falta de equipamentos urbanos à eficiência dos setores econômico e social.

Não é sem motivo que o Govêrno da União está sèriamente preocupado com o problema urbano nacional, nêle aplicando cêrca de $55 \%$ de seus recursos, que em 1970 atingiram a 4 bilhões e 200 milhões de cruzeiros. Ésse comportamento deriva da constatação de que, de um total de 95 milhões de habitantes, 45 milhões estão na área rural e 50 milhões na área urbana. A projeção para 1980 está em tôrno de 130 milhões de habitantes, tudo indicando que serão alcançados níveis superiores a 80 milhões na área urbana e inferiores a 50 milhões no meio rural.

Como tarefa preliminar para o equacionamento do assunto, visando fixar metas no que diz respeito ao crescimento urbano e ao planejamento a níveis estadual e federal, a SUDESUL, - Govêrno do Estado do Rio Grande do Sul e o SERFHAU firmaram acôrdo de cooperação com a finalidade de estabelecer uma política conjunta de desenvolvimento urbano para o Estado. Em resultado da convenção, foram contratados os serviços da Universidade Federal do Rio Grande do Sul, que realizou levantamentos, análises e estudos sôbre a dinâmica urbana e formulou proposições alternativas para o seu contrôle, trabalho elaborado com o máximo rigor técnico e entregue ao Govêrno do Estado em princípios dêste ano.

Com idênticas características, estudo dessa mesma natureza está sendo efetuado pela Universidade Federal de Santa Catarina, a fim de propor decisões relativamente ao problema do desenvolvimento urbano naquele Estado, conforme contrato assinado pela SUDESUL, com a assistência do SERFHAU e do Govêrno do Estado.

Com referência ao Plano de Desenvolvimento Local Integrado, ora em plena implantação na área regional, o definimos como o instrumento hábil a promover o desenvolvimento econômico e social de microrregiões homogêneas. Através dêle, pela interveniência das associações de municípios, a realidade será conhecida, os seus objetivos traçados, adotadas as diretrizes de desenvolvimento, e programadas as medidas de govêrno para concretizar seus objetivos, e conciliando os interêsses de crescimento local com os regionais e nacionais.

Por meio dêste Plano, o Ministério do Interior torna acessíveis aos governos municipais os instrumentos técnicos $e^{\mathrm{fi}-}$ 
nanceiros adequados ao desempenho de sua missão, ao tempo em que procura capacitá-los a adotar o planejamento integrado como processo normal de govêrno.

PESCA

Com mais de $8.500 \mathrm{~km}$ de costa, dos quais parte ponderável corresponde a uma plataforma altamente piscosa, o Brasil precisa urgentemente aproveitar de modo racional as reservas alimentícias existentes no mar, tanto mais que, como é sabido, a carne em futuro próximo poderá ser de consumo mais caro e difícil para atender à demanda do abastecimento, devido ao incremento demográfico.

Eis a razão do Decreto-lei no 221 , de 28 de fevereiro de 1967, pelo qual o Govêrno destinou vultosos recursos à pesca, visando principalmente a captura e a industrialização, medida que induziu a SUDESUL a elaborar projeto referente à distribuição, comercialização e industrialização do produto nos três Estados do sul.

Trabalho formulado e em processamento sob regime de cooperação com a SUDEPE, constitui a primeira experiência brasileira no gênero, estando concluída sua fase inicial.

A primeira parte dos estudos consistiu no levantamento de dados básicos, a partir de pesquisas efetuadas em 26 cidades sôbre a produção e o consumo do pescado, elementos que possibilitam a previsão das carências da oferta e da demanda.

Procede a SUDESUL, presentemente, à montagem de um projeto global, que determinará, entre outros indicadores, a estrutura e a localização de estabelecimentos comerciais e industriais, com as cautelas necessárias para que não venham a constituírem pontos de estrangulamento na exploração econômica que se pretende intensificar.

\section{COORDENAÇAOO REGIONAL}

tura, Está o Ministério do Interior compondo uma sólida estruto regiequada a servir a um sistema nacional de planejamenPlanejional ajustado às diretrizes emanadas do Ministério do to e Coordenação Geral.

tanco primeiro e largo passo dirigido nessa direção consubsinstituiu-se no Decreto no 66.882, de 16 de julho de 1970, que órgãos a reforma da Pasta, introduzindo modificações nos em níveis ela vinculados e submetendo-as a uma coordenação niveis nacional e macrorregional. 
Tal reformulação implicou, para os organismos regionais de planejamento - dentre os quais a Superintendência do Desenvolvimento da Região Sul (SUDESUL) - em aumento de atribuições e maior amplitude de ação, tornando-os ainda mais diretamente responsáveis pelo desenvolvimento econômico e social das respectivas áreas.

Dêsse modo, incumbe à SUDESUL a tarefa de coordenar tôda a ação ministerial na Região Sul, o que é feito através da Comissão de Coordenação Regional. Presidido pelo Superintendente da SUDESUL, o colegiado reúne as delegacias regionais dos seguintes órgãos: BNH, SERFHAU, DNOS, PROJETO RONDON, FUNAI e CLM.

O Banco Nacional da Habitação, que em breve será emprêsa pública, possui uma Delegacia Regional nesta área, com sede em Pôrto Alegre e jurisdição sôbre os três Estados do Sul. Estimulando e disciplinando os sistemas financeiros de habitação, saneamento, poupança e empréstimo, a Delegacia Regional do BNH executa o Plano Nacional de Habitação no Paraná, em Santa Catarina e no Rio Grande do Sul, com ênfase quanto ao planejamento local integrado e incremento das indústrias relacionadas à construção civil.

O planejamento local integrado, que o BNH financia, constitui atribuição específica do Serviço Federal de Habitação e Urbanismo, o qual é representado na área por uma Coordenação Regional. Em sua atuação nesse importante campo, o SERFHAU conta com a colaboração da SUDESUL e das administrações municipais e estaduais, sendo apreciável o resultado dêsse esfôrço na Região, quase tôda coberta por associações de municípios conscientizadas para o planejamento ante a política implantada.

As atividades do SERFHAU consistem na proposição de normas, roteiros básicos e padrões de desempenho, além da realização de estudos e análises de projetos, complementada com a assistência técnica às municipalidades e promoção do treinamento de seu pessoal. Não sendo órgão executivo, concentra sua ação no estabelecimento de diretrizes gerais, orientação técnica para a escolha dos escritórios de planejamento, fiscalização das emprêsas contratadas e obtenção de financiamento para a elaboração dos planos.

Nas capitais dos Estados do Paraná, de Santa Catarina e do Rio Grande do Sul, o Departamento Nacional de Obras de Saneamento mantém Distritos Federais responsáveis pela execução, no respectivo território, das obras requeridas pelo 
saneamento básico, abastecimento de água e esgotos sanitários e pluviais, combate à poluição na orla marítima, contrôle da erosão, beneficiamento de áreas e proteção contra sêcas e inundações. De acôrdo com os planos de desenvolvimento, regional e locais, o DNOS vem efetuando estudos e projetos, bem como orientando, executando e fiscalizando obras e serviços de irrigação e saneamento rural-urbano, em colaboração com Estados, Municípios, organismos públicos e privados.

Destaque especial deve ser dado ao trabalho desenvolvido com vistas à defesa contra inundações em Pôrto Alegre e Canoas, assim também no que se refere à drenagem e à irrigação de terras agrícolas nas regiões do Taim e do Camaquã, neste Estado. Ainda no Rio Grande do Sul, é de salientar-se a conclusão da Barragem Maestra, recém-inaugurada em Caxias do Sul, destinada a abastecimento de água.

Alinham-se igualmente entre as principais obras do DNOS nesta área, a canalização do Rio Ivo, em Curitiba, inaugurada no corrente ano, e as barragens de proteção do Vale do Itajaí, em Santa Catarina, empreendimento de vulto, a concluir-se totalmente em 1973.

A supervisão da atividade regional do PROJETO RONDON está confiada à Coordenação Executiva Regional do Sul, que Se empenha em engajar a juventude estudantil sulina nesse admirável movimento de sã brasilidade, cujo sentido maior reside na integração dos jovens à conjuntura nacional. Assim, tem promovido estágios para universitários e a criação de "Campi" avançados de Universidades, como o de Roraima, instalado pela Universidade de Santa Maria, o de Rondônia, pela Universidade Federal do Rio Grande do Sul, e o de Santarém, Pela Universidade Federal de Santa Catarina.

As representações regionais da Fundação Nacional do Indio observam o cumprimento da política indigenista na Região Sul, preservando a pessoa do índio e sua cultura, além de prestar ao silvícola assistência extensiva, em têrmos educacionais, sociais e médico-sanitários. A SUDESUL, em cooperação com a FUNAI, está projetando a realização de estudos sôbre as reServas indígenas regionais, a fim de conhecer a potencialidade dos recursos naturais e programar seu melhor aproveltamento.

A Seção Brasileira da Comissão Mista Brasileiro-Uruguaia, que elabora o Projeto da Lagoa Mirim, vinculada à SUDESUL através do Decreto no 66.882 , de 16 de julho de 1970 , concluiu a fase preliminar do seu trabalho, após cinco anos de 
exaustivos estudos hidrológicos, geológicos, sócio-econômicos e de sistemas de irrigação, transporte e energia. Os elementos coligidos pelas pesquisas permitem à CLM iniciar seu plano de obras, dando prioridade à construção da barragem do São Gonçalo, de urgência premente, porquanto a mesma, com evitar a salinação da Lagoa Mirim, proporcionará solução a problemas irrigatórios em vasta área adjacente e de abastecimento de água às cidades de Pelotas e Rio Grande.

FECHO

A expressão desenvolvimenta sócio-econômico algumas vêzes tem sofrido os equívocos daqueles que the subtraem ao significado aspectos que, por não serem ostensivos ou não se traduzirem em fatos concretos e cifras computáveis, escapam à percepção dos menos atentos à realidade.

Há valôres que as tabelas estatísticas não registram e os laboratórios não analisam.

Crescer, social e econômicamente, não é só TER MAIS, senão também SER MAIS; não é apenas aumentar a renda, é igualmente elevar o nivel de cultura; é não sòmente SABER MAIS, como COMPREENDER MELHOR.

Empenha-se, em síntese, o Govêrno Médici, em sensibilizar e empolgar tôdas as fôrças úteis da comunidade, engajando-as na luta árdua pelo desenvolvimento.

Já superamos o tempo em que só os Podêres Públicos eram responsáveis por tudo.

Hoje outro e luminoso é o panorama com o despertar, seguido da ação dinâmica de tôda a Nação, num esfôrço gigantesco que vem transformando o País em grande potência. 